\title{
PIK3CA Mutations in Advanced Cancers: Characteristics and Outcomes
}

Filip Janku ${ }^{1}$, Jennifer J. Wheler ${ }^{1}$, Aung Naing ${ }^{1}$, Vanda M. Stepanek ${ }^{1}$, Gerald S. Falchook $^{1}$, Siqing Fu ${ }^{1}$, Ignacio Garrido-Laguna ${ }^{1}$, Apostolia M. Tsimberidou ${ }^{1}$, Sarina A. Piha-Paul ${ }^{1}$, Stacy L. Moulder ${ }^{1}$, J. Jack Lee ${ }^{2}$, Rajyalakshmi Luthra ${ }^{3}$, David S. Hong ${ }^{1}$, Razelle Kurzrock ${ }^{4}$

${ }^{1}$ Department of Investigational Cancer Therapeutics (Phase I Clinical Trials Program), The University of Texas MD Anderson Cancer Center, Houston, Texas, USA

2 Department of Biostatistics, The University of Texas MD Anderson Cancer Center, Houston, Texas, USA

${ }^{3}$ Molecular Diagnostic Laboratory, The University of Texas MD Anderson Cancer Center, Houston, Texas, USA

${ }^{4}$ Moores Cancer Center, The University of California San Diego, La Jolla, California, USA

Correspondence to: Filip Janku, email: fjanku@mdanderson.org

Keywords: PIK3CA mutation, phenotypic taxonomy, clinical outcome

Received: October 19, 2012, Accepted: November 30, 2012, Published: November 30, 2012

Copyright: @ Janku et al. This is an open-access article distributed under the terms of the Creative Commons Attribution License, which permits unrestricted use, distribution, and reproduction in any medium, provided the original author and source are credited.

ABSTRACT:

PIK3CA mutations are frequently diagnosed in diverse cancers and may predict response to $\mathrm{PI} 3 \mathrm{~K} / \mathrm{AKT} / \mathrm{mTOR}$ inhibitors. It remains unclear whether they are associated with other characteristics. We analyzed characteristics and outcome of 90 consecutive patients with diverse advanced tumors and PIK3CA mutations and 180 wild-type PIK3CA controls matched by tumor type, gender, and age referred to the Clinical Center for Targeted Therapy. PIK3CA and MAPK mutations (KRAS, NRAS, and $B R A F$ ) were analyzed using polymerase chain reaction-based DNA sequencing. The most frequent PIK3CA mutations were E545K (31/90, 34\%), E542K (16/90, $18 \%$ ) in exon 9, and H1047R (20/90, 22\%) in exon 20. PIK3CA mutations compared to wild-type PIK3CA were associated with simultaneous KRAS $(p=0.047)$ and MAPK mutations $(p=0.03)$, but only MAPK mutations were confirmed as having an independent association in multivariate analysis. Rates of lung, bone, liver and brain metastases were similar in PIK3CA-mutant and wild-type patients. Patients with PIK3CA mutations treated on trials with PI3K/AKT/mTOR inhibitors had a higher partial/complete response (PR/CR) rate than wild-type PIK3CA patients treated with their best phase I therapy $(10 / 56,18 \%$ vs. $12 / 152,8 \% ; p=0.045)$, but not a prolonged progression-free survival. Patients with H1047R PIK3CA mutations had a higher PR/CR rate with PI3K/AKT/mTOR inhibitors compared to wild-type PIK3CA patients treated with their best phase I therapy (6/16, 38\% vs. $12 / 152,8 \%$; $\mathrm{p}=0.003$ ). In conclusion, PIK3CA mutations in diverse cancers were not associated with clinical characteristics, but were correlated with MAPK mutations. PIK3CA mutations, especially, H1047R, were associated with attaining a PR/CR to PI3K/ AKT/mTOR pathway inhibitors.

\section{INTRODUCTION}

PIK3CA mutations frequently occur in diverse cancers and are associated with constitutive activation of the PI3K/AKT/mTOR pathway.[1-5] In addition, PIK3CA mutations predicted sensitivity to PI3K/AKT/
mTOR inhibitors in multiple tumor types in preclinical and early clinical experiments.[1,2, 5-12] A seminal question is whether PIK3CA mutations are associated with a distinct phenotypic taxonomy. Retrospective studies in colorectal cancer demonstrated that PIK3CA mutations in exon 20 encoding for the kinase domain, but not in exon 
9 encoding for the helical domain, are associated with resistance to EGFR-targeting monoclonal antibodies. [13] In addition, our group reported that, regardless of histology, PIK3CA mutations often coexist with mitogenactivated protein kinase (MAPK) mutations, such as mutated $K R A S, N R A S$, and $B R A F$.[14] A partial answer to the question posed about the relationship between $P I K 3 C A$ mutations and specific subtypes of cancer is generally that different cancers seem to have different types of PIK3CA mutations and associations with still other mutations.[15] For example, in colorectal cancer PIK3CA mutations in exon 9 , but not exon 20, trended toward an association with $K R A S$ mutations, whereas only PIK3CA exon 20 mutations were associated with KRAS mutations in ovarian cancer.[13, 16] Other oncogenic mutations have also been correlated with clinical characteristics and outcome. For example patients with advanced cancers and $B R A F$ mutations have less soft tissue, retroperitoneal, lung metastases and more brain metastases.[17] In colorectal cancer, $B R A F$ mutations predicted poor outcome and $K R A S$ mutations were associated with lung metastases. $[13,18]$ We investigated characteristics and outcomes of patients with advanced cancers with and without PIK3CA mutations.

\section{METHODS}

\section{Patients}

We retrospectively reviewed clinical and pathological characteristics and treatment outcomes of 90 consecutive patients with advanced tumors harboring PIK3CA mutations who had been referred to the Clinical Center for Targeted Therapy at The University of Texas MD Anderson Cancer Center (MD Anderson) starting in October 2008. To define distinguishing features of advanced cancers with $P I K 3 C A$ mutations, we selected a control group of 180 patients with wild-type (wt) PIK3CA advanced cancers matched in a $2: 1$ ratio by tumor type, gender, and age (+/- 5 years) to patients with $P I K 3 C A$ mutations referred to the MD Anderson Clinical Center for Targeted Therapy (CCTT) during the same period of time.

Data were collected from transcribed notes and radiology reports in the electronic medical record and other source documentation. Registering patients in the database, pathology assessment, and mutation analysis were performed at MD Anderson. The study and all treatments were conducted in accordance with the guidelines of the MD Anderson Institutional Review Board.

\section{Tissue samples and mutation analyses}

PIK3CA, KRAS, NRAS, and BRAF mutations were investigated in archival formalin-fixed, paraffin-embedded tissue blocks or material from primary or metastatic lesions obtained from diagnostic and/or therapeutic procedures. All histologies were centrally reviewed at MD Anderson. Mutation testing was performed in the Clinical Laboratory Improvement Amendmentcertified Molecular Diagnostic Laboratory within the Division of Pathology and Laboratory Medicine at MD Anderson. DNA was extracted from microdissected paraffin-embedded tumor sections and analyzed using a polymerase chain reaction-based DNA sequencing method for PIK3CA mutations in codons 532-554 of exon 9 (helical domain) and codons 1011-1062 of exon 20 (kinase domain). Analysis included the mutation hot spot region of the PIK3CA proto-oncogene denoted by Sanger sequencing, following amplification of $276 \mathrm{bp}$ and 198 bp amplicons, respectively, utilizing primers designed by the MD Anderson Molecular Diagnostic Laboratory. Whenever possible, in addition to PIK3CA, mutation analysis was done for $K R A S$ and $N R A S$ codons 12,13 , and 61 mutations, and $B R A F$ codons 595-600 mutations of exon 15 by pyrosequencing, as previously described.[19]

\section{Treatment}

Prior to being treated with Phase I agents, patients typically received the US Food and Drug Administration (FDA)-approved therapy. If available, we collected data from the last FDA-approved therapy in addition to the Phase I therapy given in the CCTT. For patients with PIK3CA mutations, data were recorded for treatment received that included $\mathrm{PI} 3 \mathrm{~K} / \mathrm{AKT} / \mathrm{mTOR}$ inhibitors. For wt PIK3CA patients, data from the best phase I therapy were recorded. The response outcome was measured by partial $[\mathrm{PR}]$ or complete response $[\mathrm{CR}]$ or the absence of $\mathrm{PR} / \mathrm{CR}$ as well as the duration of progression-free survival [PFS] and overall survival (OS). [20]

\section{Statistical analysis}

Patient characteristics were summarized using descriptive statistics. Response to treatment (PR or CR) was evaluated using Response Evaluation Criteria in Solid Tumors (RECIST 1.0).[20] PFS was defined as the interval from initiation of the selected phase I treatment to disease progression or death. Patients who were alive and not progressing were censored at the date of the last follow-up. Overall survival (OS) was defined as the interval from diagnosis to death and OS on phase I therapy (OS-Ph1) was defined as the interval between recorded initiation of the systemic phase I treatment to death. 
Table 1: Patient characteristics

\begin{tabular}{|c|c|c|c|c|}
\hline Variable & Number $(\%)$ & \begin{tabular}{|l|} 
PIK3CA \\
mutation (\%)
\end{tabular} & \begin{tabular}{|l|} 
wild-type \\
PIK3CA (\%)
\end{tabular} & P value \\
\hline All & $270(100)$ & $90(100)$ & $180(100)$ & Not applicable \\
\hline \multicolumn{5}{|l|}{ Gender } \\
\hline Man & $102(38)$ & $34(38)$ & $68(38)$ & $1.00 \dagger$ \\
\hline Women & $168(62)$ & $56(62)$ & $112(62)$ & \\
\hline \multicolumn{5}{|l|}{ Age } \\
\hline$</=50$ years & $80(30)$ & $26(29)$ & $54(30)$ & $0.89 \ddagger$ \\
\hline$>50$ years & $190(70)$ & $64(71)$ & $126(70)$ & \\
\hline \multicolumn{5}{|l|}{ Ethnicity } \\
\hline Caucasian & $213(79)$ & $67(74)$ & $146(81)$ & 0.12 \\
\hline African-American & $25(9)$ & $13(14)$ & $12(7)$ & \\
\hline Hispanic & $18(7)$ & $4(5)$ & $14(8)$ & \\
\hline Asian & $14(5)$ & $6(7)$ & $8(4)$ & \\
\hline \multicolumn{5}{|l|}{ Smoking History } \\
\hline Past and current smokers & $113(42)$ & $35(39)$ & $78(43)$ & 0.52 \\
\hline Non-smokers & $157(58)$ & $55(61)$ & $102(57)$ & \\
\hline \multicolumn{5}{|l|}{ History of deep vein thrombosis } \\
\hline Yes & $53(20)$ & $24(27)$ & $29(16)$ & 0.05 \\
\hline No & $217(80)$ & $66(73)$ & $151(84)$ & \\
\hline \multicolumn{5}{|l|}{ Prior therapies } \\
\hline$</=3$ & $143(53)$ & $52(58)$ & $91(51)$ & 0.30 \\
\hline$>3$ & $127(47)$ & $38(42)$ & $89(49)$ & \\
\hline \multicolumn{5}{|l|}{ Site of Primary Tumor } \\
\hline Colorectal & $72(27)$ & $24(27)$ & $48(27)$ & $1.00 \ddagger$ \\
\hline Breast & $45(17)$ & $15(17)$ & $30(17)$ & \\
\hline Ovarian & $33(12)$ & $11(12)$ & $22(12)$ & \\
\hline Endometrial & $27(10)$ & $9(10)$ & $18(10)$ & \\
\hline Head \& neck: squamous & $24(9)$ & $8(9)$ & $16(9)$ & \\
\hline Cervical: squamous & $18(7)$ & $6(7)$ & $12(7)$ & \\
\hline Non-small cell lung & $12(4)$ & $4(4)$ & $8(4)$ & \\
\hline Other & $39(14)$ & $13(14)$ & $26(14)$ & \\
\hline \multicolumn{5}{|l|}{ Metastases } \\
\hline Lungs & $168(62)$ & $59(66)$ & $109(61)$ & 0.51 \\
\hline Liver & $168(62)$ & $55(61)$ & $113(63)$ & 0.79 \\
\hline Brain & $34(13)$ & $10(11)$ & $24(13)$ & 0.70 \\
\hline Bones & $89(33)$ & $25(28)$ & $64(36)$ & 0.22 \\
\hline \multicolumn{5}{|l|}{ Mutations } \\
\hline KRAS mutated* & $53(25)$ & $25(34)$ & $28(21)$ & 0.047 \\
\hline$K R A S$ wild-type* & $155(75)$ & $49(66)$ & $106(79)$ & \\
\hline NRAS mutated** & $3(3)$ & $1(3)$ & $2(3)$ & 1.00 \\
\hline$N R A S$ wild-type** & $92(97)$ & $31(97)$ & $61(97)$ & \\
\hline$B R A F$ mutated & $15(8)$ & $7(11)$ & $8(7)$ & 0.41 \\
\hline$B R A F$ wild-type & $164(92)$ & $58(89)$ & $106(93)$ & \\
\hline$R A S(K-$ or $N-)$ or $B R A F$ mutated $\mid \rrbracket$ & $71(54)$ & $33(66)$ & $38(46)$ & 0.03 \\
\hline$R A S(K-$ or $N-)$ and $B R A F$ wild-type $\|$ & $61(46)$ & $17(34)$ & $44(54)$ & \\
\hline
\end{tabular}

$\$$ Patients with PIK3CA mutations and controls with wild-type PIK3CA were matched by tumor type, gender, and age ( $+/-5$ years). Therefore, differences cannot be expected

*Tested for $K R A S, \mathrm{n}=208$ (PIK3CA mutation, $\mathrm{n}=74$; wild-type $P I K 3 C A, \mathrm{n}=134)$

**Tested for NRAS, $\mathrm{n}=95$ (PIK3CA mutation, $\mathrm{n}=32$; wild-type PIK3CA, $\mathrm{n}=63$ )

I Tested for $B R A F, \mathrm{n}=179$ (PIK3CA mutation, $\mathrm{n}=65$; wild-type PIK3CA, $\mathrm{n}=114$ )

qศ Tested for $R A S$ ( $K$ - or $N$-) or $B R A F, \mathrm{n}=132$ (PIK3CA mutation, $\mathrm{n}=50$; wild-type $P I K 3 C A, \mathrm{n}=82)$. Since mutations in $K R A S, N R A S, B R A F$ are considered to be mutually exclusive, patients with mutations or patients tested negative for all three mutations were included in the analysis 
Table 2: Types of $P I K 3 C A, K R A S$, $N R A S$ and $B R A F$ mutations

\begin{tabular}{|c|c|}
\hline Mutation type & $\mathbf{N}(\%)$ \\
\hline PIK3CA mutation & $90(100)$ \\
\hline E542K & $16(18)$ \\
\hline E542V & $1(<3)$ \\
\hline E545K & $31(34)$ \\
\hline E545G & $2(<3)$ \\
\hline Q546K & $2(<3)$ \\
\hline S553N & $1(<3)$ \\
\hline P539R, E545A & $1(<3)$ \\
\hline E545K, D549H & $1(<3)$ \\
\hline Exon 9 deletion & $1(<3)$ \\
\hline E545A, H1047Y & $1(<3)$ \\
\hline R1023Q & $1(<3)$ \\
\hline M1043I & $2(<3)$ \\
\hline M1043V & $2(<3)$ \\
\hline $\mathrm{D} 1045 \mathrm{~N}$ & $1(<3)$ \\
\hline H1047L & $4(4)$ \\
\hline H1047R & $20(22)$ \\
\hline G1049R & $3(3)$ \\
\hline$K R A S^{*}$ mutation & $53(100)$ \\
\hline G12A & $7(13)$ \\
\hline G12C & $4(8)$ \\
\hline G12D & $14(26)$ \\
\hline G12F & $1(<3)$ \\
\hline G12R & $3(6)$ \\
\hline G12S & $2(4)$ \\
\hline G12V & $10(19)$ \\
\hline G13D & $5(9)$ \\
\hline Q61H & $2(4)$ \\
\hline Q61L & $1(<3)$ \\
\hline Not specified & $4(8)$ \\
\hline$N R A S^{* *}$ mutations & $3(100)$ \\
\hline G13D & $1(33)$ \\
\hline Q61K & $1(33)$ \\
\hline Q61R & $1(33)$ \\
\hline BRAF & $15(100)$ \\
\hline V600E & $11(73)$ \\
\hline V600K & $3(20)$ \\
\hline V600R & $1(7)$ \\
\hline
\end{tabular}

*Tested for $K R A S, \mathrm{n}=208$, **Tested for NRAS, $\mathrm{n}=95$, T Tested for $B R A F, \mathrm{n}=179$

Patients who were alive were censored at the date of the last follow-up. Distant metastasis-free survival (DMFS) was defined as the interval from diagnosis to development of metastatic disease. The probabilities of PFS, OS, OS$\mathrm{Ph} 1$, and DMFS were estimated using the method of Kaplan and Meier and the time-to-event endpoints were compared among subgroups using the log-rank test.[21, 22]
Associations between PIK3CA mutation status and categorical variables (ethnicity, biopsy/tissue site, metastatic site, history of deep vein thrombosis [DVT], history of smoking, KRAS mutation, NRAS mutation, $B R A F$ mutation, $\mathrm{PR} / \mathrm{CR}$ status after last FDA-approved therapy, PR/CR status after PI3K/AKT/mTOR targeted phase I therapy in PIK3CA-mutant patients, or status after the best phase I therapy in wt PIK3CA patients) were assessed using Fisher's exact test. PR/CR rate to prior vs. current therapies in matched paired subjects was assessed using McNemar's test. In addition, univariate and multivariate logistic regression models were fit to assess the associations between PIK3CA mutations and other categorical variables. A Cox regression model was applied to assess the effect of covariates on time-to-event endpoints. All tests were two-sided, and a P value less than 0.05 was considered statistically significant. All statistical analyses were carried out using SPSS 17 computer software (SPSS Chicago, IL) and R version 2.15.0 (R Foundation for Statistical Computing).

\section{RESULTS}

\section{Patient characteristics}

A total of 270 patients with diverse advanced cancers consisting of 90 patients with PIK3CA mutations and 180 controls with wt PIK3CA (matched by tumor type, gender, and age) were analyzed and their clinical and pathologic characteristics are listed in Table 1. Most patients $(79 \%)$ were white and women $(62 \%)$. The median age was 56 years (range, 16-83) and patients received the median number of 3 prior therapies (range, 0-12). The most prevalent tumor types were colorectal cancer $(27 \%)$, breast cancer $(17 \%)$, ovarian cancer $(12 \%)$ and endometrial cancer (10\%). Lung and/or liver metastases were found in $62 \%$ of patients. Brain metastases were found in $13 \%$ of patients. Of the 208 patients tested for $K R A S, 53(25 \%)$ had a mutation; of the 95 tested for NRAS, 3 (3\%) had a mutation; and of the 179 tested for $B R A F, 15(8 \%)$ had a mutation. When analyzing tested MAPK mutations, of the 132 patients tested for KRAS, $N R A S$, and $B R A F$ mutation status (patients were selected for analyses if they had a mutation in $K R A S$, or NRAS, or $B R A F$ since they are known to be mutually exclusive or if they were tested negative for all 3 oncogenes), 71 (54\%) had KRAS, NRAS or BRAF mutations.

\section{Mutation types}

Of the 90 patients with PIK3CA mutations, 56 (62\%) had mutations in exon 9 coding for the helical domain, 33 $(37 \%)$ in exon 20 coding for the kinase domain, and 1 (1\%) had a dual mutation in exons 9 and 20. The most 
Table 3: Outcomes in patients with $P I K 3 C A$ mutations and wild-type PIK3CA patients

\begin{tabular}{|c|c|c|c|c|c|}
\hline Cancer & Outcome & PIK3CA mutation & wild-type $P I K 3 C A$ & OR or HR $(95 \% \mathrm{CI})$ & P value \\
\hline \multirow[t]{7}{*}{ All } & PR/CR last FDA & $5 / 59(8 \%)$ & $6 / 138(4 \%)$ & $\begin{array}{l}\text { OR 2.04 } \\
(95 \% \text { CI } 0.60-6.96) \\
\end{array}$ & 0.31 \\
\hline & PR/CR Phase I & $10 / 56(18 \%)$ & $12 / 152(8 \%)$ & $\begin{array}{l}\text { OR 2.74 } \\
(95 \% \text { CI 1.07.-7.01) }\end{array}$ & 0.045 \\
\hline & $\begin{array}{l}\text { PFS on last } \\
\text { FDA }(95 \% \mathrm{CI})\end{array}$ & $\begin{array}{l}3.0 \text { months } \\
(95 \% \text { CI } 2.6-3.4)\end{array}$ & $\begin{array}{l}3.2 \text { months ( } \\
95 \% \text { CI } 2.5-3.9)\end{array}$ & $\begin{array}{l}\text { HR } 1.01 \\
(95 \% \text { CI } 0.80-1.50)\end{array}$ & 0.55 \\
\hline & $\begin{array}{l}\text { PFS on Phase I } \\
(95 \% \mathrm{CI})\end{array}$ & $\begin{array}{l}2.0 \text { months } \\
(95 \% \text { CI } 1.4-2.6)\end{array}$ & $\begin{array}{l}3.7 \text { months } \\
(95 \% \text { CI 3.2-4.2) }\end{array}$ & $\begin{array}{l}\text { HR } 1.10 \\
(95 \% \text { CI } 0.78-1.56)\end{array}$ & 0.59 \\
\hline & DMFS $(95 \%$ CI) & \begin{tabular}{|l|}
12.3 months \\
$(95 \%$ CI $7.5-17.1)$ \\
\end{tabular} & \begin{tabular}{|l|}
18.8 months \\
$(95 \%$ CI $14.5-23.1)$ \\
\end{tabular} & \begin{tabular}{|l|} 
HR 1.08 \\
$(95 \%$ CI $0.77-1.53)$ \\
\end{tabular} & 0.64 \\
\hline & OS $(95 \% \mathrm{CI})$ & $\begin{array}{l}50.4 \text { months } \\
\text { (95\% CI 36.2-64.6) }\end{array}$ & $\begin{array}{l}55.2 \text { months } \\
(95 \% \text { CI } 46.7-63.7)\end{array}$ & $\begin{array}{l}\text { HR } 1.07 \\
(95 \% \text { CI } 0.77-1.47) \\
\end{array}$ & 0.70 \\
\hline & OS-Ph1 $(95 \%$ CI $)$ & $\begin{array}{l}6.6 \text { months } \\
(95 \% \text { CI 3.9-9.3) }\end{array}$ & \begin{tabular}{|l|}
8.6 months \\
$(95 \%$ CI $7.1-10.1)$ \\
\end{tabular} & $\begin{array}{l}\text { HR } 1.49 \\
(95 \% \text { CI } 1.04-2.14) \\
\end{array}$ & 0.03 \\
\hline \multirow[t]{7}{*}{ Colorectal } & $\begin{array}{l}\mathrm{PR} / \mathrm{CR} \text { last FDA } \\
(\mathrm{n}=55)\end{array}$ & $1 / 18(6 \%)$ & $0 / 37(0 \%)$ & NA & 0.34 \\
\hline & $\begin{array}{l}\text { PR/CR Phase I } \\
(\mathrm{n}=47)\end{array}$ & $0 / 14(0 \%)$ & $0 / 33(0 \%)$ & NA & NA \\
\hline & PFS on last FDA & $\begin{array}{l}2.8 \text { months } \\
(95 \% \text { CI } 1.6-4.0)\end{array}$ & \begin{tabular}{|l}
4.3 months \\
$(95 \%$ CI $3.3-5.3)$ \\
\end{tabular} & \begin{tabular}{|l|} 
HR 1.62 \\
$(95 \%$ CI $0.90-2.92)$ \\
\end{tabular} & 0.10 \\
\hline & PFS on Phase I & $\begin{array}{l}1.8 \text { months } \\
(95 \% \text { CI } 1.5-2.1)\end{array}$ & $\begin{array}{l}3.8 \text { months } \\
(95 \% \text { CI 3.5-4.1) }\end{array}$ & $\begin{array}{l}\text { HR } 1.86 \\
(95 \% \text { CI } 0.93-3.73)\end{array}$ & 0.07 \\
\hline & DMFS & $\begin{array}{l}15.2 \text { months } \\
(95 \% \text { CI 5.3-25.1) }\end{array}$ & $\begin{array}{l}18.8 \text { months } \\
(95 \% \text { CI } 4.4-33.2)\end{array}$ & $\begin{array}{l}\text { HR } 0.99 \\
(95 \% \text { CI } 0.43-2.29)\end{array}$ & 1.00 \\
\hline & OS & $\begin{array}{l}45.1 \text { months } \\
\text { (95\% CI 36.3-53.9) }\end{array}$ & $\begin{array}{l}54.0 \text { months } \\
(95 \% \text { CI 33.2-74.8) }\end{array}$ & $\begin{array}{l}\text { HR } 1.13 \\
(95 \% \text { CI } 0.62-2.06)\end{array}$ & 0.70 \\
\hline & OS-Ph1 & $\begin{array}{l}3.6 \text { months } \\
(95 \% \text { CI } 2.5-4.7)\end{array}$ & $\begin{array}{l}10.3 \text { months } \\
(95 \% \text { CI } 6.6-14.0)\end{array}$ & $\begin{array}{l}\text { HR 3.05 } \\
(95 \% \text { CI 1.51-6.18) }\end{array}$ & 0.001 \\
\hline
\end{tabular}

Abbreviations: CI, confidence interval; FDA, Food and Drug Administration; HR, hazard ratio; NA, not applicable; OR, odds ratio; PR/CR, partial or complete response; PFS, progression-free survival; DMFS, distant metastases-free survival; OS-Ph1, overall survival on phase I therapy; OS, overall survival from diagnosis

frequent mutation types were E545K $(1633 \mathrm{G}>\mathrm{A})$ in 31 (34\%) patients, followed by mutated H1047R $(3140 \mathrm{~A}>\mathrm{G})$ in $20(22 \%)$ patients and $\mathrm{E} 542 \mathrm{~K}(1624 \mathrm{G}>\mathrm{A})$ mutations in $16(18 \%)$ patients (Table 2$)$.

Of the 53 patients with KRAS mutations, 14 $(26 \%)$ had a G12D mutation (35G>A), 10 (19\%) a G12V mutation (35G>T), 7 (13\%) had a G12A mutation $(35 \mathrm{G}>\mathrm{C}), 5(9 \%)$ had a G13D mutation $(38 \mathrm{G}>\mathrm{A})$ and 17 $(32 \%)$ had other mutations (Table 2).

Of the 3 patients with $N R A S$ mutations, 1 (33\%) had a G13D mutation (38G $>$ A), $1(33 \%)$ had a Q61K mutation $(181 \mathrm{C}>\mathrm{A})$ and $1(33 \%)$ had a Q61R mutation $(182 \mathrm{~A}>\mathrm{G})$ (Table 2).

Of the 15 patients with $B R A F$ mutations, $11(73 \%)$ had a V600E mutation (1799_1800TG>AA), 3 (20\%) a V600K mutation (1798_1799GT $>$ AA), and 1 (7\%) a V600R mutation (1798_1799GT $>$ AG) (Table 2).

For $K R A S, N R A S$, and $B R A F$ mutations, no patient had more than one type of mutation within each gene, which is not surprising since these mutations are known to be mutually exclusive. $[13,23]$

\section{Clinical and molecular features associated with PIK3CA mutations}

Patients with $P I K 3 C A$ mutations $(\mathrm{n}=90)$ compared to patients with wt PIK3CA $(\mathrm{n}=180)$ had a trend to a higher incidence of DVT (24/90 [27\%] vs. 29/180 [16\%], $\mathrm{p}=0.05)$, higher prevalence of KRAS mutations $(25 / 74$ [34\%] vs. 28/134 [21\%], p=0.047), and a higher prevalence of mutations in the MAPK pathway (KRAS, $N R A S$, or $B R A F$ mutations) $(33 / 50$ [66\%] vs. 38/82 [46\%], $\mathrm{p}=0.03$ ) (Table 1). There was no difference with respect to ethnicity, smoking history, number of prior therapies, biopsy/tissue site, and the occurrence of lung, liver, bone, and brain metastases between patients with and without PIK3CA mutations (Table 1). The multivariate regression model, which included MAPK mutation status and history of DVT, confirmed that patients with PIK3CA mutations had a higher prevalence of MAPK mutations (odds ratio 
[OR] 2.19, 95\% confidence interval [CI] 1.05-4.59, $\mathrm{p}=0.04)$.

Disease-specific subanalyses showed a trend toward an association between PIK3CA and KRAS mutations in colorectal cancer (17/24 [71\%] vs. 21/44 [48\%]; $\mathrm{p}=0.08)$ and associations between PIK3CA mutations and KRAS mutations $(6 / 17[35 \%]$ vs. $2 / 28[7 \%], p=0.04)$ and MAPK mutations $(8 / 13[62 \%]$ vs. $2 / 15[13 \%], p=0.02)$ in ovarian and endometrial cancers combined.

In addition, in all tumor types we analyzed clinical and molecular associations separately for PIK3CA mutations in exon 9 (helical domain) and exon 20 (kinase domain), and found that PIK3CA mutations in exon 9 compared to others (wt PIK3CA, PIK3CA exon 20 mutations) had a trend toward an association with simultaneous KRAS mutations (17/46 [37\%] vs. 36/162 [22\%]; $\mathrm{p}=0.05)$, had a trend toward association with $B R A F$ mutations $(6 / 42$ [14\%] vs. 9/137 [7\%]; $p=0.12)$, and was significantly associated with MAPK mutations (23/33 [70\%] vs. 48/99 [48\%]; $\mathrm{p}=0.04)$. PIK3CA mutations in exon 20 compared to others (wt PIK3CA, PIK3CA exon 9 mutations) were not associated with $K R A S$ mutations $(8 / 28$ [29\%] vs. $45 / 180$ [25\%]; $\mathrm{p}=0.65), B R A F$ mutations $(1 / 23[7 \%]$ vs. $14 / 156[13 \%] ; p=0.70)$, or MAPK mutations $(10 / 17$ [59\%] vs. 61/115 [53\%]; p=0.80). In addition, PIK3CA mutations in exon 9 compared to others demonstrated a trend toward an association with a history of DVT (16/56 [29\%] vs. 37/214 [17\%]; p=0.09). There were no other associations with any other assessed characteristics (ethnicity, smoking history, number of prior therapies, biopsy/tissue site, and the occurrence of lung, liver, bone, and brain metastases).

\section{Treatment outcomes with respect to PIK3CA mutation status}

We analyzed $\mathrm{PR} / \mathrm{CR}$ rates from the last FDAapproved treatment in 197 patients with available data and found no statistically significant differences between patients with PIK3CA mutations and wt PIK3CA patients $(5 / 59$ [8\%] vs. $6 / 138$ [4\%], $\mathrm{p}=0.31)$ (Table 3$)$. In contrast, in 208 patients who received phase I systemic therapy, those with PIK3CA mutations treated with a phase I therapy targeting the PI3K/AKT/mTOR pathway had a higher PR/CR rate than wt $P I K 3 C A$ patients treated with their best phase I therapy $(10 / 56[18 \%]$ vs. $12 / 152$ [8\%], $\mathrm{p}=0.045$ ). We also analyzed PR/CR rate following phase I therapy separately for patients with exon 9 and those with exon 20 PIK3CA mutations. Patients with PIK3CA exon 9 mutations showed a trend toward a higher PR/ $\mathrm{CR}$ rate to the phase I therapy with a PI3K/AKT/mTOR inhibitor than patients with wt $P I K 3 C A$ treated with their best phase I therapy $(4 / 30[13 \%]$ vs. $6 / 138[4 \%], \mathrm{p}=0.08)$. Patients with PIK3CA exon 20 mutations had a higher PR/ CR rate after phase I therapy with a $\mathrm{PI} 3 \mathrm{~K} / \mathrm{AKT} / \mathrm{mTOR}$ inhibitor compared to patients with wt PIK3CA treated with their best phase I therapy (6/25 [24\%] vs. 6/138 [4\%], $\mathrm{p}=0.004)$. In addition, we analyzed $\mathrm{PR} / \mathrm{CR}$ rate sfrom the phase I therapy separately for patients with the most frequent mutations: E545K ( $\mathrm{n}=31), \mathrm{H} 1047 \mathrm{R}(\mathrm{n}=20)$, and E542K ( $n=16)$. While there was no difference in PR/CR rates in patients with E545K or E542K mutations, patients with H1047R treated with a PI3K/AKT/mTOR inhibitor compared to wt PIK3CA treated with their best phase I therapy demonstrated higher $\mathrm{PR} / \mathrm{CR}$ rates(6/16 [38\%] vs. $12 / 152$ [8\%]; $p=0.003)$.

We next analyzed PFS after the last FDA-approved therapy $(n=197)$ and phase I systemic therapy $(n=208)$ (Table 3). There was no significant difference in median PFS following the last FDA-approved therapy between patients with PIK3CA mutations (3 months, 95\% CI 2.63.4 ) and wt PIK3CA (3.2 months, 95\%CI 2.5-3.9, $\mathrm{p}=0.55$ ). Similarly, there was no significant difference in median PFS after treatment with a phase I therapy targeting the PI3K/AKT/mTOR pathway in PIK3CA-mutant patients (2 months, 95\% CI 1.4-2.6) versus treatment with the best systemic phase I therapy in wt PIK3CA patients (3.7 months, $95 \%$ CI 3.2-4.2, $\mathrm{p}=0.59$ ). We also analyzed PFS from the phase I therapy separately for patients with exon 9 and exon 20 PIK3CA mutations. Patients with $P I K 3 C A$ exon 9 mutations did not have a significantly different median PFS on phase I therapy compared to patients with wt PIK3CA (2 months [95\%CI 1.9-2.1] vs. 3.7 months [95\%CI 3.2-4.2], $\mathrm{p}=0.41$ ). Similarly, patients with PIK3CA exon 20 mutations had no significantly different median PFS after phase I therapy compared to patients with wt PIK3CA (1.9 months [95\%CI 0.8-3.0] vs. 3.7 months [95\%CI 3.3-4.1], $\mathrm{p}=0.77$ ). Patients with H1047R mutations compared to wt PIK3CA did not have a significantly different median PFS (5.7 months [95\% CI $0.9-10.5$ ] vs. 3.7 months [95\%CI 3.2-4.2], $\mathrm{p}=0.26$ ).

Next, we performed paired analysis in 143 patients who had available data for treatment with the last FDAapproved therapy and who then received subsequent phase I systemic therapy to compare $\mathrm{PR} / \mathrm{CR}$ rate and $\mathrm{PFS}$ in these subgroups. Patients with PIK3CA mutations had a similar PR/CR rate in response to treatment with phase I therapies targeting the PI3K/AKT/mTOR pathway than to their previous FDA-approved therapy (5/36 [14\%] vs. $2 / 36[6 \%], p=0.38$ ) (Table 4). There was no statistically significant difference in a median PFS on the last FDAapproved therapy (3.6 months, $95 \%$ CI $2.8-4.4$ ) or phase I therapy targeting PI3K/AKT/mTOR (2.8 months, $95 \% \mathrm{CI}$ 1.3-4.3) in patients with PIK3CA mutations ( $\mathrm{p}=0.60$ ). Patients with wt $P I K 3 C A$ had a similar PR/CR rate to the best phase I and the last FDA-approved therapies (6/107 [6\%] vs. 7/107 [7\%], $p=1.00$ ). There was no statistically significant difference in median PFS after the last FDAapproved therapy (3.5 months, 95\% CI 2.7-4.3) and after the best phase I therapy (3.6 months, $95 \%$ CI 3.1-4.4.1) in patients with PIK3CA mutations ( $\mathrm{p}=0.37$ ). 
Table 4: Paired analysis of treatment outcomes on last FDA-approved and phase I therapy

\begin{tabular}{|l|l|l|l|l|}
\hline Patients & Outcome & FDA approved & Phase I & P value \\
\hline All PIK3CA mutations & PR/CR & $2 / 36(6 \%)$ & $5 / 36(14 \%)$ & 0.38 \\
\hline & PFS & 3.6 months (95\% CI 2.8-4.4) & 2.8 months (95\% CI 1.3-4.3) & 0.60 \\
\hline All wt PIK3CA & PR/CR & $6 / 107(6 \%)$ & $7 / 107(7 \%)$ & 1.00 \\
\hline & PFS & 3.5 months (95\% CI 2.7-4.3) & 3.6 months (95\% CI 3.1-4.1) & 0.37 \\
\hline Colorectal PIK3CA mutations & PR/CR & $0 / 10(0 \%)$ & $0 / 10(0 \%)$ & 1.00 \\
\hline & PFS & 3.7 months (95\% CI 2.0-5.4) & 1.7 months (95\% CI 1.2-2.2) & 0.01 \\
\hline Colorectal wt PIK3CA & PR/CR & $0 / 25(0 \%)$ & $0 / 25(0 \%)$ & 1.00 \\
\hline & PFS & 5.0 months (95\% CI 4.1-5.9) & 3.9 months (95\% CI 3.2-4.6) & 0.34 \\
\hline
\end{tabular}

Abbreviations: CI, confidence interval; FDA, Food and Drug Administration; PR/CR, partial or complete response; PFS, progression-free survival; wt, wild-type

Finally we analyzed OS (measured from diagnosis), OS-Ph1 (measured from recorded phase I therapy), and DMFS (measured from diagnosis to metastatic disease) for patients with PIK3CA mutations and wt PIK3CA patients (Table 3). Patients with PIK3CA mutations had a similar median OS (50.4 months, 95\% CI 36.2-64.6) as patients with wt PIK3CA (55.2 months, 95\% CI 46.7-63.7, $\mathrm{p}=0.70)$. In 142 patients who were initially diagnosed with localized disease, those with PIK3CA mutations had a numerically shorter DMFS (12.3 months, 95\% CI 7.517.1) than patients with wt PIK3CA (18.8 months, 95\% CI 14.5-23.1, $\mathrm{p}=0.6$ ). In 208 patients who received phase I therapy, those with PIK3CA mutations had a shorter median Ph1-OS (6.6 months, 95\% CI 3.9-9.3) than patients with wt PIK3CA (8.6 months, 95\% CI 7.1-10.1, $\mathrm{p}=0.03$ ).

Colorectal cancer was the largest tumor-specific subgroup, consisting of 24 patients with PIK3CA mutations and 48 matched wt PIK3CA controls. We therefore performed subanalysis on this histology. PIK3CA mutations were most frequent in exon $9(16 / 24$ [67\%]) (Supplementary Table 1). PIK3CA mutations were not significantly associated with any specific clinical characteristics, although there was a trend to a lower prevalence of liver metastases compared to patients with wt PIK3CA (16/24 [67\%] vs. 40/48 [83\%], p=0.14) (Supplementary Table 2). In patients tested for KRAS mutations, those with PIK3CA mutations compared to wt PIK3CA demonstrated a trend to having a higher prevalence of KRAS mutations (17/24 [71\%] vs. 21/44 [48\%]; $\mathrm{p}=0.08$ ) (Supplementary Table 2). In a separate analysis, $P I K 3 C A$ exon 9 mutations compared to others had a trend to a higher frequency of KRAS mutations $(12 / 16$ [75\%] vs. 26/52 [50\%]; p=0.09), whereas PIK3CA exon 20 mutations compared to others showed no association with $K R A S$ mutations (5/8 [63\%] vs. $33 / 60$ $[55 \%] ; \mathrm{p}=1.00)$.

There was no significant difference between colorectal cancer patients with PIK3CA mutations and wt
PIK3CA in PR/CR rate to the last line of FDA-approved therapy $(1 / 18[6 \%]$ vs. $0 / 37[0 \%] ; \mathrm{p}=0.34)$ (Table 3). Patients with PIK3CA mutations had no response to PI3K/ AKT/mTOR-targeted phase I therapies and, similarly, wt PIK3CA patients did not respond to the best phase I therapy $(0 / 14[0 \%]$ vs. $0 / 33[0 \%] ; p=1.00)$.

Colorectal cancer patients with PIK3CA mutations compared to wt $P I K 3 C A$ demonstrated a trend to a shorter median PFS to the last FDA-approved therapy (2.8 months [1.6-4.0] vs. 4.3 months [3.3-5.3]; $\mathrm{p}=0.10$ ) (Table 3). Similarly, patients with PIK3CA mutations treated with a PI3K/AKT/mTOR targeted therapy compared to $\mathrm{wt}$ PIK3CA patients treated with their best phase I therapy showed a trend to a shorter median PFS (1.8 months [1.5$2.1]$ vs. 3.8 months [3.5-4.1]; $\mathrm{p}=0.07)$.

A paired analysis of colorectal cancer patients for whom we had data on the last FDA-approved therapy and phase I therapy (PIK3CA mutations, $\mathrm{n}=10$; wt PIK3CA, $\mathrm{n}=25$ ), there was no response noted (Table 4). PIK3CA mutant patients had a significantly longer PFS on the last FDA-approved therapy compared to phase I PI3K/AKT/ mTOR targeted therapy (3.7 months $[2.0-5.4]$ vs. 1.7 months [1.2-2.2]; $\mathrm{p}=0.01$ ). In wt PIK3CA patients, there was no significant difference in median PFS on the last FDA-approved therapy compared to best phase I therapy (5 months [4.1-5.9] vs. 3.9 months [3.2-4.6], $\mathrm{p}=0.34$ ).

Finally, there was no significant difference in OS, OS-Ph1, and DMFS between colorectal cancer patients with PIK3CA mutations and wt PIK3CA (Table 3).

\section{DISCUSSION}

In this study of 90 patients with PIK3CA mutations and 180 wt PIK3CA controls (matched by tumor type, gender, and age) we identified having a history of DVT as the only clinical characteristic potentially associated with PIK3CA mutations. However, this association was not confirmed by multivariate analysis. None of the clinical characteristics including ethnicity, the site of metastases, 
smoking history, number of prior therapies, OS, OS-Ph1, DMFS was associated with $P I K 3 C A$ status.

In agreement with previous reports, when assessing individuals for MAPK mutations we noted the association between PIK3CA and MAPK mutations (66\% vs. 46\%, $\mathrm{p}=0.03)$ and between $P I K 3 C A$ and $K R A S$ mutations (34\% vs. $21 \%, \mathrm{p}=0.047)$. $[13,14]$ In disease-specific subanalyses, also in agreement with previous reports, there was a trend toward an association between $P I K 3 C A$ and $K R A S$ mutations in colorectal cancer $(71 \%$ vs. $48 \%$, $\mathrm{p}=0.08)$; associations between PIK3CA and KRAS $(35 \%$ vs. $7 \%, \mathrm{p}=0.04)$, and $P I K 3 C A$ and MAPK mutations $(62 \%$ vs. $13 \%, \mathrm{p}=0.02$ ) in ovarian and endometrial cancers. [13, 14] We also looked for associations linked to mutations in exon 9 and exon 20, which account for more than $80 \%$ of PIK3CA mutations.[24] Overall, PIK3CA exon 9 mutations were associated with simultaneous MAPK mutations ( $70 \%$ vs. $48 \%$; $\mathrm{p}=0.04)$, showed a trend toward association with simultaneous KRAS mutations (37\% vs. $22 \%$; $=0.05)$, and albeit a weaker trend toward association with $B R A F$ mutations ( $14 \%$ vs. $7 \%$; $=0.12)$, whereas PIK3CA exon 20 mutations were not associated with any mutations in the MAPK pathway. This finding is consistent with previous reports from our group and others in colorectal cancer and other tumor histologies.[13, 14]

Oncogenic mutations often point to the presence of a therapeutic target that might be amenable to directed therapeutic intervention. For example, KIT mutations render patients with gastrointestinal stromal tumor sensitive to KIT tyrosine kinase inhibitors (TKIs), EGFR mutations render patients with NSCLC sensitive to EGFR TKIs, a $E M L 4-A L K$ fusion renders patients with NSCLC sensitive to ALK inhibitors, and BRAF mutations increase the sensitivity of melanoma patients to BRAF inhibitors. [25-28] We reported increased PR/CR rates in response to $\mathrm{PI} 3 \mathrm{~K} / \mathrm{AKT} / \mathrm{mTOR}$ inhibitors in patients with $P I K 3 C A$ mutations compared to wt $P I K 3 C A$ treated in early phase clinical trials.[8] In the current study, we retrospectively evaluated treatment outcomes (PR/CR rate, PFS) on the last FDA-approved therapy and phase I therapy (therapy targeting $\mathrm{PI} 3 \mathrm{~K} / \mathrm{AKT} / \mathrm{mTOR}$ pathway in patients with $P I K 3 C A$ mutations or best phase I therapy [defined by $\mathrm{CR} / \mathrm{PR}$ or longest PFS] in patients with wt $P I K 3 C A)$. Overall, there was no difference in $\mathrm{PR} / \mathrm{CR}$ rate $(8 \%$ vs. $4 \% ; \mathrm{p}=0.31)$ and PFS (3.0 months vs. 3.2 months, $\mathrm{p}=0.55)$ to the last FDA-approved therapy between patients with $P I K 3 C A$ mutations and wt PIK3CA, but patients with $P I K 3 C A$ mutations had a higher $\mathrm{PR} / \mathrm{CR}$ rate to phase I therapy with PI3K/AKT/mTOR inhibitors (18\% vs. $8 \%$; $\mathrm{p}=0.045)$, which did not, however, translate to a longer PFS (2.0 months vs. 3.7 months; $\mathrm{p}=0.59$ ) compared to wt PIK3CA patients treated with their best phase I therapy. In the paired analysis, which included only patients who had available data from treatment with both the last FDA-approved therapy and phase I therapy, we found no difference in $\mathrm{PR} / \mathrm{CR}$ rates and PFS in patients with
$P I K 3 C A$ mutations and wt PIK3CA. The explanation for this might be because $\mathrm{PI} 3 \mathrm{~K} / \mathrm{AKT} / \mathrm{mTOR}$ targeting therapies are effective in only a subset of patients. In NSCLC, specific EGFR mutations such as exon 19 deletions or exon 21 mutations (L858R), render tumors sensitive to EGFR TKIs, whereas an exon 20 mutation (T790M) is associated with therapeutic resistance. [29] A similar scenario is possible for other oncogenic mutations. Indeed, in our current study we noticed that patients with $\mathrm{H} 1047 \mathrm{R} P I K 3 C A$ mutations compared to patients with wt $P I K 3 C A$ had an increased $\mathrm{PR} / \mathrm{CR}$ rate ( $38 \%$ vs. $8 \% ; \mathrm{p}=0.003)$ to phase I therapy compared to wt $P I K 3 C A$ patients. Another explanation might relate to the histological milieu of the PIK3CA mutations. Although, these mutations were found in a variety of cancers, the largest subgroup of patients had colorectal cancer. These patients showed a poor outcome on PI3K/AKT/mTOR, perhaps because of the frequent coexistence of $K R A S$ mutations in this histology.[13, 14, 30]

Finally, we investigated whether PIK3CA mutations have prognostic significance. For instance, EGFR mutations compared to wt EGFR in NSCLC are usually associated with improved treatment outcomes and a longer OS.[31] KRAS mutations in NSCLC are associated with poor outcomes in response to EGFR therapies.[31] In colorectal cancer, BRAF mutations are associated with a shorter survival.[13] Consensus regarding the impact of PIK3CA mutations is contradictory. Some investigators reported better prognosis in certain cancers such as breast cancer with $P I K 3 C A$ mutations, whereas others suggested that $P I K 3 C A$ mutations indicate a worse prognosis in colorectal cancer, endometrial cancer and NSCLC.[13, 29, 32-36] There was no significant difference in patients with $P I K 3 C A$ mutations and wt PIK3CA in OS (from the time of first diagnosis; 50.4 months vs. 55.2 months; $\mathrm{p}=0.70$ ), and DMFS (from time of first diagnosis to development of metastatic disease; 12.3 months vs. 18.8 months; $\mathrm{p}=0.64$ ); however, patients with $P I K 3 C A$ mutations had a shorter OS-Ph1 (from initiation of phase I therapy; 6.6 months vs. 8.6 months; $p=0.03$ ). In disease-specific sub-analyses, we found a lower survival in patients with colorectal cancer and PIK3CA mutations who, compared to wt PIK3CA patients, experienced a shorter OS-Ph1 (3.6 months vs. 10.3 months; $\mathrm{p}=0.001)$. This finding provides another piece of evidence suggesting that colorectal cancer patients with PIK3CA mutations do not do well on a PI3K/ $\mathrm{AKT} / \mathrm{mTOR}$ targeted therapy.

In conclusion, in the current study of 90 patients with $P I K 3 C A$ mutations and 180 matched controls with wt $P I K 3 C A$ we found that there was no PIK3CA phenotype. Overall, $P I K 3 C A$ mutations were associated with $K R A S$ and MAPK (KRAS, NRAS, BRAF) mutations. Patients with $P I K 3 C A$ mutations treated with $\mathrm{PI} 3 \mathrm{~K} / \mathrm{AKT} / \mathrm{mTOR}$ axis inhibitors had a $\mathrm{PR} / \mathrm{CR}$ rate of $18 \%$. This $\mathrm{PR} / \mathrm{CR}$ rate is lower than the rate we previously reported for gynecologic and breast malignancies, in which the PR/ 
CR rate was $30 \%$, and may be due to the fact that the largest subgroup (colorectal cancer) in this paper did not respond well to $\mathrm{PI} 3 \mathrm{~K} / \mathrm{AKT} / \mathrm{mTOR}$ axis therapy even in the presence of PIK3CA mutations.[16] The lack of response may be due to the high rate of concomitant MAPK mutations in colorectal cancer. Finally, patients with PIK3CA H1047R mutations in exon 20 appeared to have the most favorable PR/CR rate, but this observation requires confirmation in a larger cohort of patients.

\section{Conflict of interest:}

Filip Janku has research support from Novartis. Razelle Kurzrock has research support from GlaxoSmithKline, Novartis, Merck, and Bayer.

\section{ACKNOWLEDGEMENTS}

We thank Ms. Joann Aaron for scientific review and editing of this article.

\section{REFERENCE}

1. Engelman JA, Chen L, Tan X, Crosby K, Guimaraes AR, Upadhyay R, Maira M, McNamara K, Perera SA, Song Y, Chirieac LR, Kaur R, Lightbown A, Simendinger J, Li T, Padera RF, et al. Effective use of PI3K and MEK inhibitors to treat mutant Kras G12D and PIK3CA H1047R murine lung cancers. Nat Med. 2008; 14(12):1351-1356.

2. Yuan W, Stawiski E, Janakiraman V, Chan E, Durinck S, Edgar KA, Kljavin NM, Rivers CS, Gnad F, RooseGirma M, Haverty PM, Fedorowicz G, Heldens S, Soriano $\mathrm{RH}$, Zhang Z, Wallin JJ, et al. Conditional activation of Pik3ca(H1047R) in a knock-in mouse model promotes mammary tumorigenesis and emergence of mutations. Oncogene. 2012.

3. Schwarz JK, Payton JE, Rashmi R, Xiang T, Jia Y, Huettner P, Rogers BE, Yang Q, Watson M, Rader JS and Grigsby PW. Pathway-specific analysis of gene expression data identifies the PI3K/Akt pathway as a novel therapeutic target in cervical cancer. Clin Cancer Res. 2012; 18(5):1464-1471.

4. Miller TW, Balko JM and Arteaga CL. Phosphatidylinositol 3-kinase and antiestrogen resistance in breast cancer. J Clin Oncol. 2011; 29(33):4452-4461.

5. Adams JR, Schachter NF, Liu JC, Zacksenhaus E and Egan SE. Elevated PI3K signaling drives multiple breast cancer subtypes. Oncotarget. 2011; 2(6):435-447.

6. Ihle NT, Lemos R, Jr., Wipf P, Yacoub A, Mitchell C, Siwak D, Mills GB, Dent P, Kirkpatrick DL and Powis G. Mutations in the phosphatidylinositol-3-kinase pathway predict for antitumor activity of the inhibitor PX-866 whereas oncogenic Ras is a dominant predictor for resistance. Cancer Res. 2009; 69(1):143-150.
7. Di Nicolantonio F, Arena S, Tabernero J, Grosso S, Molinari F, Macarulla T, Russo M, Cancelliere C, Zecchin D, Mazzucchelli L, Sasazuki T, Shirasawa S, Geuna M, Frattini M, Baselga J, Gallicchio M, et al. Deregulation of the PI3K and KRAS signaling pathways in human cancer cells determines their response to everolimus. J Clin Invest. 2010; 120(8):2858-2866.

8. Janku F, Tsimberidou AM, Garrido-Laguna I, Wang X, Luthra R, Hong DS, Naing A, Falchook GS, Moroney JW, Piha-Paul SA, Wheler JJ, Moulder SL, Fu S and Kurzrock R. PIK3CA Mutations in Patients with Advanced Cancers Treated with PI3K/AKT/mTOR Axis Inhibitors. Mol Cancer Ther. 2011; 10(3):558-565.

9. Shimizu T, Tolcher AW, Papadopoulos KP, Beeram M, Rasco DW, Smith LS, Gunn S, Smetzer L, Mays TA, Kaiser B, Wick MJ, Alvarez C, Cavazos A, Mangold GL and Patnaik A. The Clinical Effect of the Dual-Targeting Strategy Involving PI3K/AKT/mTOR and RAS/MEK/ERK Pathways in Patients with Advanced Cancer. Clin Cancer Res. 2012;18(8):2316-25.

10. Weigelt B, Warne PH and Downward J. PIK3CA mutation, but not PTEN loss of function, determines the sensitivity of breast cancer cells to mTOR inhibitory drugs. Oncogene. 2011; 30(29):3222-3233.

11. Weber GL, Parat MO, Binder ZA, Gallia GL and Riggins GJ. Abrogation of PIK3CA or PIK3R1 reduces proliferation, migration, and invasion in glioblastoma multiforme cells. Oncotarget. 2011; 2(11):833-849.

12. Garrett JT, Chakrabarty A and Arteaga CL. Will PI3K pathway inhibitors be effective as single agents in patients with cancer? Oncotarget. 2011; 2(12):1314-1321.

13. De Roock W, Claes B, Bernasconi D, De Schutter J, Biesmans B, Fountzilas G, Kalogeras KT, Kotoula V, Papamichael D, Laurent-Puig P, Penault-Llorca F, Rougier P, Vincenzi B, Santini D, Tonini G, Cappuzzo F, et al. Effects of KRAS, BRAF, NRAS, and PIK3CA mutations on the efficacy of cetuximab plus chemotherapy in chemotherapy-refractory metastatic colorectal cancer: a retrospective consortium analysis. Lancet Oncol. 2010; 11(8):753-762.

14. Janku F, Lee JJ, Tsimberidou AM, Hong DS, Naing A, Falchook GS, Fu S, Luthra R, Garrido-Laguna I and Kurzrock R. PIK3CA mutations frequently coexist with RAS and BRAF mutations in patients with advanced cancers. PLoS One. 2011; 6(7):e22769.

15. Chaft JE, Arcila ME, Paik PK, Lau C, Riely GJ, Pietanza MC, Zakowski MF, Rusch V, Sima CS, Ladanyi M and Kris MG. Coexistence of PIK3CA and other oncogene mutations in lung adenocarcinoma-rationale for comprehensive mutation profiling. Mol Cancer Ther. 2012; 11(2):485-491.

16. Janku F, Wheler JJ, Westin SN, Moulder SL, Naing A, Tsimberidou AM, Fu S, Falchook GS, Hong DS, GarridoLaguna I, Luthra R, Lee JJ, Lu KH and Kurzrock R. $\mathrm{PI} 3 \mathrm{~K} / \mathrm{AKT} / \mathrm{mTOR}$ inhibitors in patients with breast and gynecologic malignancies harboring PIK3CA mutations. J 
Clin Oncol. 2012;30(8):777-82.

17. El-Osta H, Falchook G, Tsimberidou A, Hong D, Naing A, Kim K, Wen S, Janku F and Kurzrock R. BRAF mutations in advanced cancers: clinical characteristics and outcomes. PLoS One. 2011; 6(10):e25806.

18. Tie J, Lipton L, Desai J, Gibbs P, Jorissen RN, Christie M, Drummond KJ, Thomson BN, Usatoff V, Evans PM, Pick AW, Knight S, Carne PW, Berry R, Polglase A, McMurrick $\mathrm{P}$, et al. KRAS mutation is associated with lung metastasis in patients with curatively resected colorectal cancer. Clin Cancer Res. 2011; 17(5):1122-1130.

19. Zuo Z, Chen SS, Chandra PK, Galbincea JM, Soape M, Doan S, Barkoh BA, Koeppen H, Medeiros LJ and Luthra R. Application of COLD-PCR for improved detection of KRAS mutations in clinical samples. Mod Pathol. 2009; 22(8):1023-1031.

20. Therasse P, Arbuck SG, Eisenhauer EA, Wanders J, Kaplan RS, Rubinstein L, Verweij J, Van Glabbeke M, van Oosterom AT, Christian MC and Gwyther SG. New guidelines to evaluate the response to treatment in solid tumors. European Organization for Research and Treatment of Cancer, National Cancer Institute of the United States, National Cancer Institute of Canada. J Natl Cancer Inst. 2000; 92(3):205-216.

21. Kaplan EM, P. Nonparametric estimator from incomplete observations. J American Statistical Association. 1958; 53:457-481.

22. Mantel N. Evaluation of survival data and two new rank order statistics arising in its consideration. Cancer Chemother Rep. 1966; 50(3):163-170.

23. Goel VK, Lazar AJ, Warneke CL, Redston MS and Haluska FG. Examination of mutations in BRAF, NRAS, and PTEN in primary cutaneous melanoma. J Invest Dermatol. 2006; 126(1):154-160.

24. Engelman JA. Targeting PI3K signalling in cancer: opportunities, challenges and limitations. Nat Rev Cancer. 2009; 9(8):550-562.

25. van Oosterom AT, Judson I, Verweij J, Stroobants S, Donato di Paola E, Dimitrijevic S, Martens M, Webb A, Sciot R, Van Glabbeke M, Silberman S and Nielsen OS. Safety and efficacy of imatinib (STI571) in metastatic gastrointestinal stromal tumours: a phase I study. Lancet. 2001; 358(9291):1421-1423.

26. Maemondo M, Inoue A, Kobayashi K, Sugawara S, Oizumi S, Isobe H, Gemma A, Harada M, Yoshizawa H, Kinoshita I, Fujita Y, Okinaga S, Hirano H, Yoshimori K, Harada T, Ogura $\mathrm{T}$, et al. Gefitinib or chemotherapy for non-smallcell lung cancer with mutated EGFR. N Engl J Med. 2010; 362(25):2380-2388.

27. Kwak EL, Bang YJ, Camidge DR, Shaw AT, Solomon B, Maki RG, Ou SH, Dezube BJ, Janne PA, Costa DB, Varella-Garcia M, Kim WH, Lynch TJ, Fidias P, Stubbs $\mathrm{H}$, Engelman JA, et al. Anaplastic lymphoma kinase inhibition in non-small-cell lung cancer. N Engl J Med.
2010; 363(18):1693-1703.

28. Flaherty KT, Puzanov I, Kim KB, Ribas A, McArthur GA, Sosman JA, O’Dwyer PJ, Lee RJ, Grippo JF, Nolop K and Chapman PB. Inhibition of mutated, activated BRAF in metastatic melanoma. N Engl J Med. 2010; 363(9):809-819.

29. Janku F, Garrido-Laguna I, Petruzelka LB, Stewart DJ and Kurzrock R. Novel therapeutic targets in non-small cell lung cancer. J Thorac Oncol . 2011; 6(9):1601-1612.

30. Chappell WH, Steelman LS, Long JM, Kempf RC, Abrams SL, Franklin RA, Basecke J, Stivala F, Donia M, Fagone P, Malaponte G, Mazzarino MC, Nicoletti F, Libra M, Maksimovic-Ivanic D, Mijatovic S, et al. Ras/Raf/MEK/ ERK and PI3K/PTEN/Akt/mTOR inhibitors: rationale and importance to inhibiting these pathways in human health. Oncotarget. 2011; 2(3):135-164.

31. Douillard JY, Shepherd FA, Hirsh V, Mok T, Socinski MA, Gervais R, Liao ML, Bischoff H, Reck M, Sellers MV, Watkins CL, Speake G, Armour AA and Kim ES. Molecular Predictors of Outcome With Gefitinib and Docetaxel in Previously Treated Non-Small-Cell Lung Cancer: Data From the Randomized Phase III INTEREST Trial. J Clin Oncol. 2010; 28(5):744-752.

32. Ludovini V, Bianconi F, Pistola L, Chiari R, Minotti V, Colella R, Giuffrida D, Tofanetti FR, Siggillino A, Flacco A, Baldelli E, Iacono D, Mameli MG, Cavaliere A and Crino L. Phosphoinositide-3-kinase catalytic alpha and KRAS mutations are important predictors of resistance to therapy with epidermal growth factor receptor tyrosine kinase inhibitors in patients with advanced non-small cell lung cancer. J Thorac Oncol .2011; 6(4):707-715.

33. He Y, Van't Veer LJ, Mikolajewska-Hanclich I, van Velthuysen ML, Zeestraten EC, Nagtegaal ID, van de Velde CJ and Marijnen CA. PIK3CA mutations predict local recurrences in rectal cancer patients. Clin Cancer Res 2009; 15(22):6956-6962.

34. Ogino S, Nosho K, Kirkner GJ, Shima K, Irahara N, Kure S, Chan AT, Engelman JA, Kraft P, Cantley LC, Giovannucci EL and Fuchs CS. PIK3CA mutation is associated with poor prognosis among patients with curatively resected colon cancer. J Clin Oncol 2009; 27(9):1477-1484.

35. Kalinsky K, Jacks LM, Heguy A, Patil S, Drobnjak M, Bhanot UK, Hedvat CV, Traina TA, Solit D, Gerald W and Moynahan ME. PIK3CA mutation associates with improved outcome in breast cancer. Clin Cancer Res . 2009; 15(16):5049-5059.

36. Catasus L, Gallardo A, Cuatrecasas M and Prat J. PIK3CA mutations in the kinase domain (exon 20) of uterine endometrial adenocarcinomas are associated with adverse prognostic parameters. Mod Pathol. 2008; 21(2):131-139. 